12

\title{
Получение наноразмерных порошков оксида вольфрама и вольфрама
}

\author{
(C) Х.А. Абдуллин ${ }^{1}$, А.А. Азаткалиев ${ }^{1}$, М.Т. Габдуллин ${ }^{2}$, Ж.К. Калкозова ${ }^{1}$, \\ Б.Н. Мукашев ${ }^{3}$, А.С. Серикканов ${ }^{3}$
}

${ }^{1}$ Национальная нанотехнологическая лаборатория, Казахский национальный университет им. аль-Фараби,

Алматы, Казахстан

${ }^{2}$ Казахстанско-Британский технический университет,

Алматы, Казахстан

${ }^{3}$ Физико-технический институт,

Алматы, Казахстан

E-mail: kh.a.abdullin@mail.ru

(Поступила в Редакцию 10 июня 2018 г.

В окончательной деракции 29 июня 2018 г.)

Нанопорошки оксида вольфрама и металлического вольфрама получены путем пиролиза метавольфрамата аммония. Применены два метода синтеза оксида вольфрама: с использованием матрицы из волокнистых материалов и пиролиз аэрозольных частиц. Частицы оксида вольфрама формировались при проведении пиролиза на воздухе. Наночастицы металлического вольфрама получены последующим термическим восстановлением оксида вольфрама в водороде. Структура и морфология образцов исследована методами рентгеноструктурного анализа и сканирующей электронной микроскопии. В зависимости от температуры синтеза получены нанопорошки вольфрама со средними размерами от 7 до $30 \mathrm{~nm}$. Электрохимические характеристики электродов, покрытых синтезированными наночастицами вольфрама, были исследованы с использованием методов циклической вольтамперометрии, импедансной спектроскопии и гальваностатического заряда-разряда. Электрод с наночастицами $\mathrm{W}$ показал удельную низкочастотную емкость около $90 \mathrm{~F} / \mathrm{g}$, возникающую благодаря тонкой пленке оксида вольфрама на поверхности наночастиц вольфрама.

Работа выполнена при поддержке гранта Комитета науки Министерства образования и науки Республики Казахстан ИРН АР05130100.

DOI: 10.21883/FTT.2019.01.46907.158

\section{1. Введение}

Металлические и оксидные наночастицы имеют высокий потенциал практического применения благодаря их уникальным свойствам [1,2], поэтому развитие низкозатратных методов синтеза наночастиц с необходимыми свойствами весьма актуально. Вольфрам и его оксиды находят практическое применение во многих областях. Оксид вольфрама и композиты на его основе перспективны для изготовления газовых и химических сенсоров [3-7], электрохромных материалов [8-10], электрокатализаторов $[11,12]$, фотокатализаторов $[13,14]$. Большое количество работ посвящено изготовлению из $\mathrm{WO}_{3}$ электродов для конденсаторов [15-17], и продемонстрирована перспективность композитов на основе наночастиц оксида вольфрама для создания суперконденсаторов.

Потенциальные практические применения оксида вольфрама и наночастиц вольфрама стимулируют исследования по развитию методов синтеза. Наночастицы металлического вольфрама могут быть получены рядом методов, такими, как осаждение с помощью CVD (chemical vapor deposition) метода, магнетронным распылением, сольвотермическим разложением и т.д. [18-20].

В настоящей работе показано, что наночастицы металлического вольфрама перспективны для создания кон- денсаторных электродов, описаны простые методы получения нанопорошков оксидов вольфрама и водородного восстановления оксида до металлического вольфрама с получением электродного материала с высокой удельной емкостью.

\section{2. Экспериментальная часть}

Нанопорошки металлического вольфрама были получены в настоящей работе в процессе двухэтапного синтеза. На первом этапе проводилось термическое разложение прекурсора - соли вольфрама, с получением наночастиц оксида вольфрама. На втором этапе проводилось водородное восстановление оксида с получением металлического вольфрама.

Материал прекурсора был выбран в виде соединения вольфрама - аммония метавольфрамата гидрата $\left(\mathrm{NH}_{4}\right)_{6} \mathrm{H}_{2} \mathrm{~W}_{12} \mathrm{O}_{40} \times \mathrm{H}_{2} \mathrm{O}$ (Sigma Aldrich). При получении наночастиц методом пиролиза для ограничения размеров синтезированных частиц требуется обеспечить лимитированное поступление материала прекурсора к формирующимся частицам. Пиролиз проводился двумя способами. В первом способе ограничение скорости поступления прекурсоров для формирования наночастиц обеспечивается использованием матрицы из волок- 
нистых материалов, в качестве которой использована натуральная целлюлоза в виде бумажных беззольных фильтров либо ваты. Водным раствором прекурсора с концентрацией $0.2 \mathrm{M}$ по вольфраму пропитывали матрицу. После сушки соль вольфрама равномерно распределяется по поверхности волокнистой матрицы. Выбором концентрации исходного раствора можно достичь весьма низкой и контролируемой объемной концентрации вещества прекурсора. Если при последующем пиролизе не допускать преждевременного распада матрицы и нивелировать роль термической диффузии, то частицы прекурсора и, соответственно, продукты пиролиза, будут распределены с низкой объемной концентрацией, что позволяет получать продукты пиролиза с контролируемыми размерами.

Раствор с матричным материалом обрабатывали в ультразвуковой ванне в течение $30 \mathrm{~min}$ для достижения однородности, затем следовал отжим и вакуумная сушка, после чего проводился термический отжиг в течение $\sim 1$ h. Скорость нагрева до целевой температуры отжига составляла $1-3^{\circ} \mathrm{C} / \mathrm{min}$. Температура отжига варьировалась от 400 до $700^{\circ} \mathrm{C}$. Отжиг проводился на воздухе с получением оксида вольфрама, для получения металлического вольфрама образцы отжигали в потоке водорода.

Во втором способе наночастицы оксида вольфрама формируются при пиролизе аэрозоля водного раствора метавольфрамата аммония. Ультразвуковой генератор аэрозоля на основе ультразвукового пьезоизлучателя продувался транспортным газом, и газовый поток с каплями аэрозоля направлялся в вертикальную трубчатую печь. В горячей зоне печки происходил пиролиз аэрозоля с формированием частиц оксида вольфрама, которые переносились газовым потоком в электростатический пылевой фильтр, расположенный на выходе газового потока из горячей зоны. Наночастицы вольфрама получены путем термического водородного восстановления оксида вольфрама.

Фазовый анализ (XRD - X-ray diffraction) осуществлялся на дифрактометре MiniFlex Rigaku. Рентгенограммы порошков сняты в излучении $\mathrm{CuK \alpha}$. Рамановские спектры были сняты на установке Ntegra Spectra (NT-MDT) с возбуждением синим лазером с длиной волны $473 \mathrm{~nm}$. Морфологию поверхности изучали с помощью сканирующего электронного микроскопа (SEM) Quanta3D200i FEI. Измерения электрохимических характеристик, циклической вольтамперометрии, а также гальваностатические измерения заряда/разряда проводились с помощью потенциостата Elins P-40X с модулем измерения электрохимического импеданса FRA-24M в трехэлектродной электрохимической ячейке в кислотном $\left(0.1 \mathrm{MH}_{2} \mathrm{SO}_{4}\right)$ электролите. В качестве противоэлектрода использовался платиновый электрод, опорным электродом был хлорсеребряный $(\mathrm{Ag} / \mathrm{AgCl})$ электрод сравнения.

\section{3. Результаты и обсуждение}

Образцы оксида вольфрама синтезированы пиролизом при температурах $400-700^{\circ} \mathrm{C}$ на воздухе, в результа- те чего получены наночастицы оксида вольфрама. Все $\mathrm{XRD}$-линии в порошках $\mathrm{WO}_{3}$, полученных пиролизом с использованием матрицы из волокнистых материалов, совпадают с эталоном JCPDS No-01-083-0950 для моноклинной модификации оксида вольфрама с пространственной группой $P 21 / n$. Полуширина линий XRD, a значит, и средний размер частиц оксида вольфрама зависела от температуры синтеза. Наиболее мелкие порошки получены при низких температурах. Средний размер кристаллитов определялся по рентгеновским данным, с использованием формулы Дебая-Шеррера

$$
\beta^{2}=\left\{\frac{0.9 \lambda}{D \cos \Theta}\right\}^{2}+\{4 \varepsilon \tan \Theta\}^{2}+\beta_{0}^{2},
$$

где $\beta$ и $\beta_{0}$ - полуширина рефлекса и инструментальная ширина линии, $\lambda$ - длина волны рентгеновских лучей, $D-$ средний размер кристаллитов или областей когерентного рассеяния, $\Theta-$ угол между отражающей плоскостью и падающим лучом, $\varepsilon-$ микронапряжения. Оценка размеров кристаллитов $\mathrm{WO}_{3}$ по полуширине рефлексов с использованием формулы (1) дает величину $\sim 7 \mathrm{~nm}$ для образца, полученного при $400^{\circ} \mathrm{C}$, и около $30 \mathrm{~nm}$ для образца, полученного при $700^{\circ} \mathrm{C}$.

$\mathrm{XRD}$-линии в порошках $\mathrm{WO}_{3}$, полученных пиролизом аэрозольных частиц, содержат не только рефлексы моноклинной модификации $\mathrm{WO}_{3}$ с пространственной группой симметрии $P 21 / n$, но и рефлексы гексагонального beta$\mathrm{WO}_{3}$ (карточка JCPDS No-01-085-2459), причем с понижением температуры синтеза вклад метастабильной гексагональной бета-фазы возрастает и при $400^{\circ} \mathrm{C}$ эта фаза становится основной.

Рамановские спектры полученных образцов оксида вольфрама также свидетельствуют о малых размерах кристаллитов. Хорошо известные полосы (например, [21]) моноклинного оксида вольфрама при 807, 716 и $274 \mathrm{~cm}^{-1}$ при низкой $\left(400^{\circ} \mathrm{C}\right)$ температуре синтеза располагались при частотах 798, 683 и $251 \mathrm{~cm}^{-1}$, и наряду со сдвигом частоты, полосы имели значительную ширину. Образцы $\mathrm{WO}_{3}$, полученные при температурах синтеза $700^{\circ} \mathrm{C}$ и выше, демонстрировали рамановские спектры, полностью совпадающие с литературными данными для моноклинного $\mathrm{WO}_{3}$.

Образцы оксида вольфрама были восстановлены в потоке водорода при температурах от 550 до $850^{\circ} \mathrm{C}$ в течение $1 \mathrm{~h}$. На рис. 1 приведены XRD-результаты для порошков металлического вольфрама (W), полученные из оксида вольфрама, синтезированного с использованием матрицы из волокнистых материалов. Из рисунка видно, что основной фазой в образцах является металлический вольфрам, о чем свидетельствует совпадение рентгенограмм образцов с XRD-эталоном для кубического вольфрама (JCPDS card No. 04-0806). Полуширина рефлексов XRD зависит от температуры синтеза.

Наиболее мелкие порошки вольфрама получены при низких температурах синтеза и водородного восстановления. Нижняя граница ограничена температурой прохождения пиролиза и реакции синтеза, поэтому 

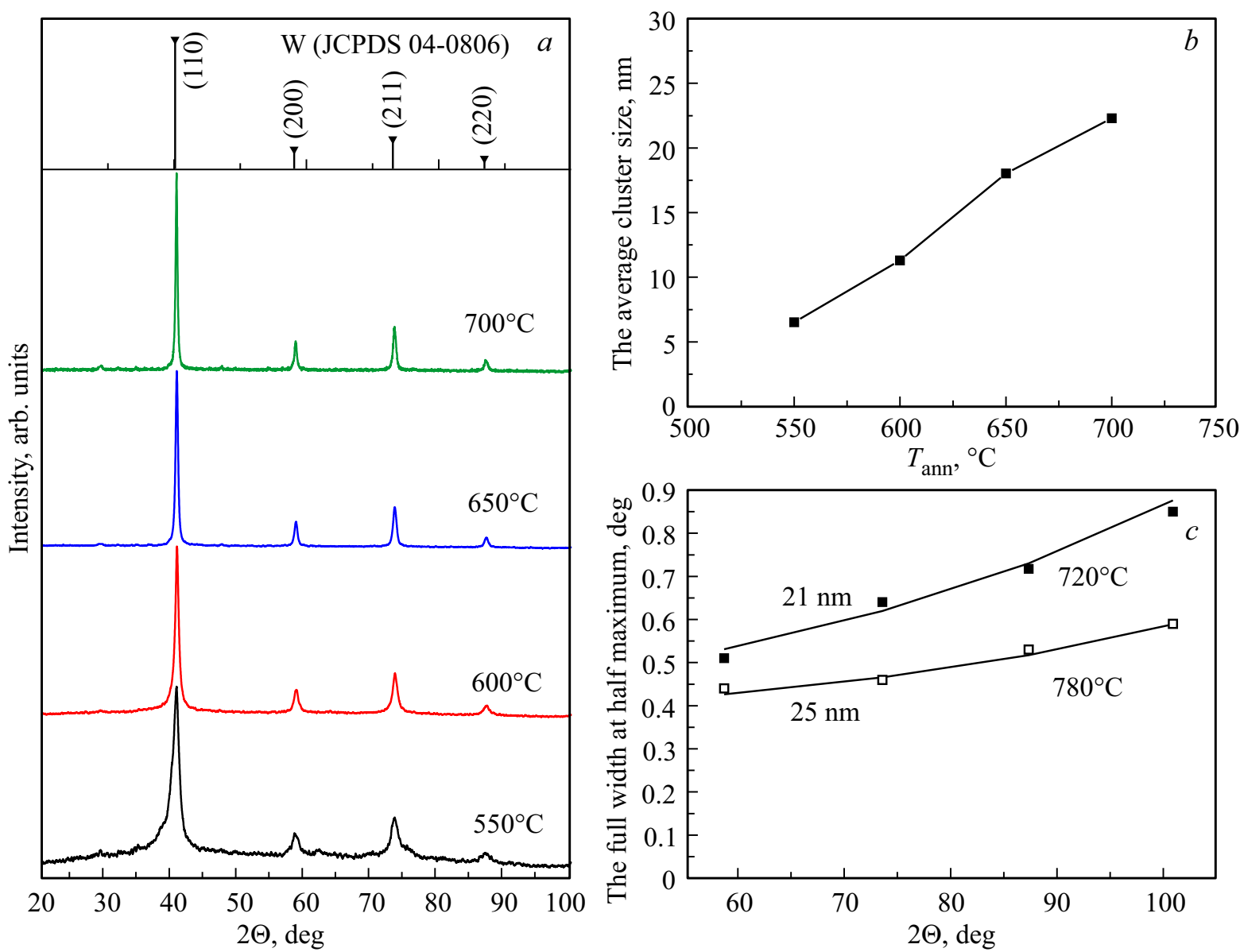

Рис. 1. $a-\mathrm{XRD}$-результаты для образцов вольфрама, которые получены из синтезированных на воздухе при $400^{\circ} \mathrm{C}$ порошков $\mathrm{WO}_{3}$ путем восстановления в потоке водорода при температурах от 550 до $700^{\circ} \mathrm{C} ; b-$ зависимость среднего размера нанокристаллов W от температуры восстановления; $c$ - зависимости полуширины XRD-рефлексов для образцов, восстановленных при 720 и $780^{\circ} \mathrm{C}$, от угла дифракции $2 \Theta$.

низкотемпературный синтез требует большего времени. С ростом температуры отжига линии сужаются, то есть размеры кристаллитов в образцах растут. Средний размер кристаллитов (размер областей когерентного рассеяния рентгеновского излучения) определялся из ширины дифракционных рефлексов по формуле (1).

Результаты оценки размеров кристаллитов по полуширине рефлексов с использованием формулы (1), но без учета микронапряжений, приведены на рис. $1, b$, где показан средний размер кристаллитов в зависимости от температуры водородного восстановления оксида вольфрама.

C ростом температуры размеры частиц W быстро увеличиваются с $6.5 \mathrm{~nm}$ для образца, полученного при водородном восстановлении при $550^{\circ} \mathrm{C}$, до $\sim 25 \mathrm{~nm}$ для образца, полученного при $700^{\circ} \mathrm{C}$. На рис. $1, c$ приведены экспериментальные данные по полуширине рентгеновских рефлексов для образцов, восстановленных при температурах 720 и $780^{\circ} \mathrm{C}$, в зависимости от угла дифракции, а также расчетные (по формуле 1) зависимости для размеров кристаллитов 21 и $25 \mathrm{~nm}$ с учетом микронапряжений. Размеры кристаллитов в этом случае получаются весьма близкими к значениям, полученным по упрощенной оценке размеров кристаллитов без учета микронапряжений.

Заметим, что XRD-рентгенограммы образцов металлического вольфрама, полученных восстановлением оксида вольфрама, синтезированного пиролизом аэрозоля водного раствора метавольфрамата аммония, кроме рефлексов кубического вольфрама (W-04-0806), содержат рефлексы метастабильной фазы вольфрама (W-beta 03-065-6453). Синтез $\mathrm{WO}_{3}$ проводился в интервале температур от 400 до $650^{\circ} \mathrm{C}$, затем все образцы $\mathrm{WO}_{3}$ были восстановлены при $500^{\circ} \mathrm{C}$ в водороде. При понижении температуры синтеза $\mathrm{WO}_{3}$, как было отмечено выше, наблюдается рост вклада гексагонального beta- $\mathrm{WO}_{3}$. Coответственно после восстановления $\mathrm{WO}_{3}$ доля метастабильной beta-фазы вольфрама растет, и для синтеза при $400^{\circ} \mathrm{C}$ соотношение фаз стабильного и метастабильного вольфрама примерно одинаковое.

На рис. 2, $a$ приведены SEM-снимки порошков оксида вольфрама, полученных пиролизом аэрозоля. Средний диаметр сферических частиц оксида вольфрама слабо зависел от температуры пиролиза, в отличие от раз- 

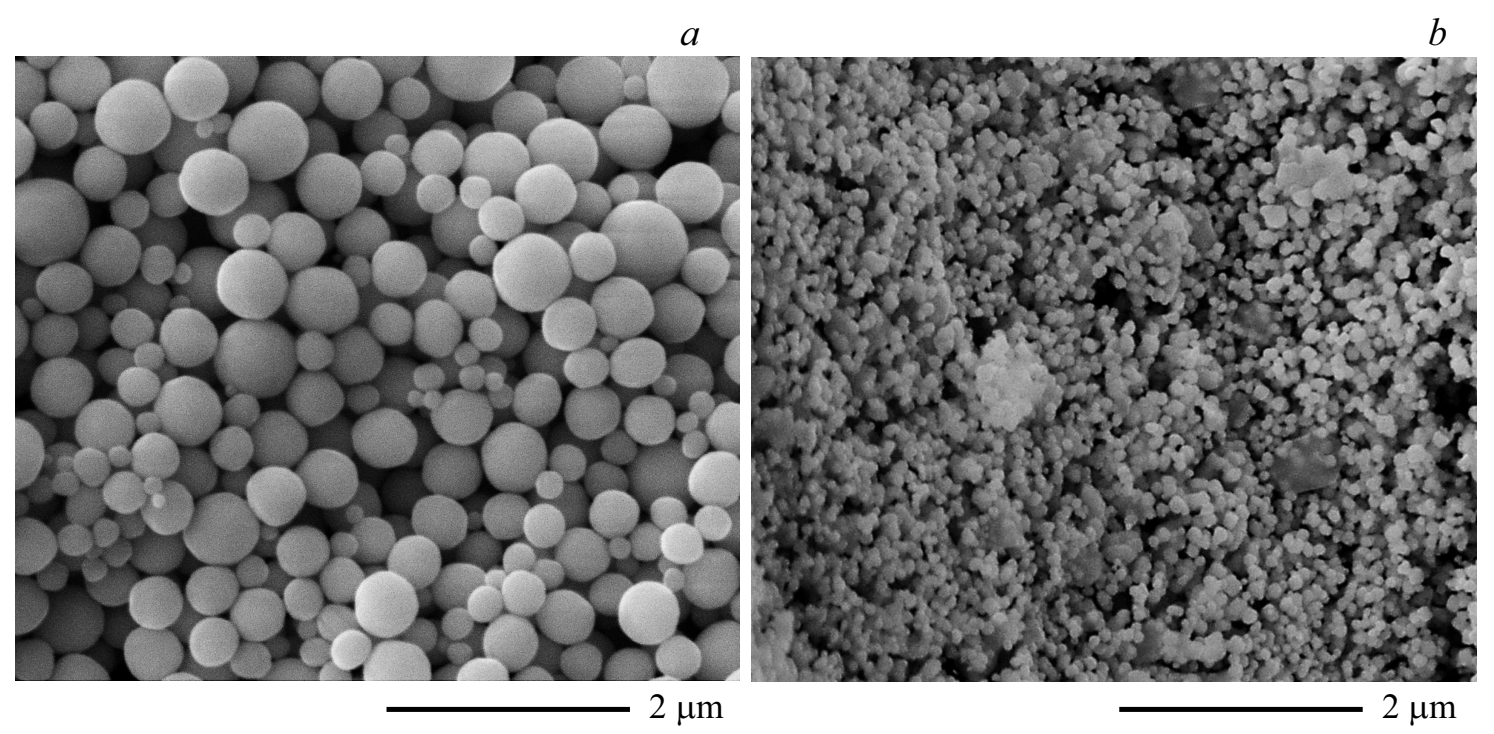

Рис. 2. SЕМ-снимки полученных образцов: $a-$ порошок оксида вольфрама, полученный пиролизом аэрозоля при $450^{\circ} \mathrm{C}$; $b$ - порошок металлического вольфрама, полученного из оксида $\mathrm{WO}_{3}$, синтезированного при температуре $400^{\circ} \mathrm{C}$ с использованием волокнистой матрицы и восстановленного в атмосфере водорода при температуре $850^{\circ} \mathrm{C}$.

мера кристаллитов. Например, для случая синтеза при температуре $450^{\circ} \mathrm{C}$, показанного на рис. $2, a$, размер кристаллитов, определенный из XRD данных, составлял $\sim 25 \mathrm{~nm}$, в то время как размер частиц варьируется от $\sim 150$ до $\sim 800 \mathrm{~nm}$ (рис. 2, $a$ ). Таким образом, синтез $\mathrm{WO}_{3}$ путем пиролиза аэрозоля приводит к формированию частиц, состоящих из множества нанокристаллов.

На рис. 2, $b$ приведены SEM- снимки порошков вольфрама. Для получения этого образца на первой стадии был проведен синтез оксида вольфрама с использованием волокнистой матрицы, а затем металлический вольфрам был получен путем восстановления $\mathrm{WO}_{3}$ в водородной атмосфере при $850^{\circ} \mathrm{C}$. Заметим, что в отличие от метода пиролиза аэрозоля, в этом методе размеры кристаллитов близки к размерам частиц. Из рис. 2, $b$ видно, что размеры кристаллитов при высокой температуре восстановления достаточно большие, около $70 \mathrm{~nm}$. Таким образом, варьирование температуры синтеза с использованием волокнистой матрицы и водородного восстановления является удобным способом получения нанокристаллов необходимых размеров с небольшим отклонением от среднего размера.

Проведены эксперименты по определению электрохимических характеристик электродов, полученных с добавлением нанопорошков оксида вольфрама и вольфрама. Электрохимические измерения проводились в трехэлектродной электрохимической ячейке с электродом из фольги из нержавеющей стали площадью $\sim 0.1 \mathrm{~cm}^{2}$ в качестве рабочего электрода. Суспензия образца в этаноле наносилась на рабочий электрод, после сушки порошок запрессовывался в электрод с помощью 12тонного гидравлического пресса. Затем электрод подвергался кратковременной обработке в ультразвуковой ванне для удаления слабо закрепленного порошка.
Электрохимические характеристики измерялись методами циклической вольтамперометрии (CV), гальваностатическими измерениями заряда-разряда и импедансометрии.

На рис. 3, а приведены кривые CV (кривые 1 и 2) электрода с впрессованным порошком вольфрама, синтезированным пиролизом с использованием волокнистой матрицы и последующего восстановления. Масса порошка вольфрама, нанесенного на электрод, определялась по разности масс исходного электрода и после прессования, и для электрода, результаты измерений которого приведены на рис. 3, составила 0.0006 g. Для сравнения на рис. 3, а приведена вольтамперограмма исходного стального электрода (кривая 3). Из сравнения кривых 1 и 3 на рис. 3, $a$ видно, что емкость электрода из нержавеющей стали растет весьма значительно при добавлении небольшого количества порошка металлического вольфрама. Более того, удельная емкость электрода с вольфрамом была выше по сравнению со случаем электрода с оксидом вольфрама.

Для получения более подробной информации о емкостных характеристиках электрода с металлическим вольфрамом были измерены кривые $\mathrm{CV}$ с различными скоростями сканирования. Значения удельной емкости, вычисленные по CV-кривым, полученным при линейной развертке потенциала с постоянной скоростью от $6 \mathrm{mV} / \mathrm{s}$ до $540 \mathrm{mV} / \mathrm{s}$, показаны на рис. $3, b$ (кривая 1 ). Низкочастотная емкость электрода с $\mathrm{W}$ составила $\sim 90 \mathrm{~F} / \mathrm{g}$.

Проведены измерения импеданса электрода при нулевом постоянном токе. Зависимость мнимой части сопротивления от действительной - годограф Найквиста для исследованного электрода, приведена на рис. 3, . Наилучшая аппроксимация полученных данных соответствует модели ячейки с параллельно включенной 

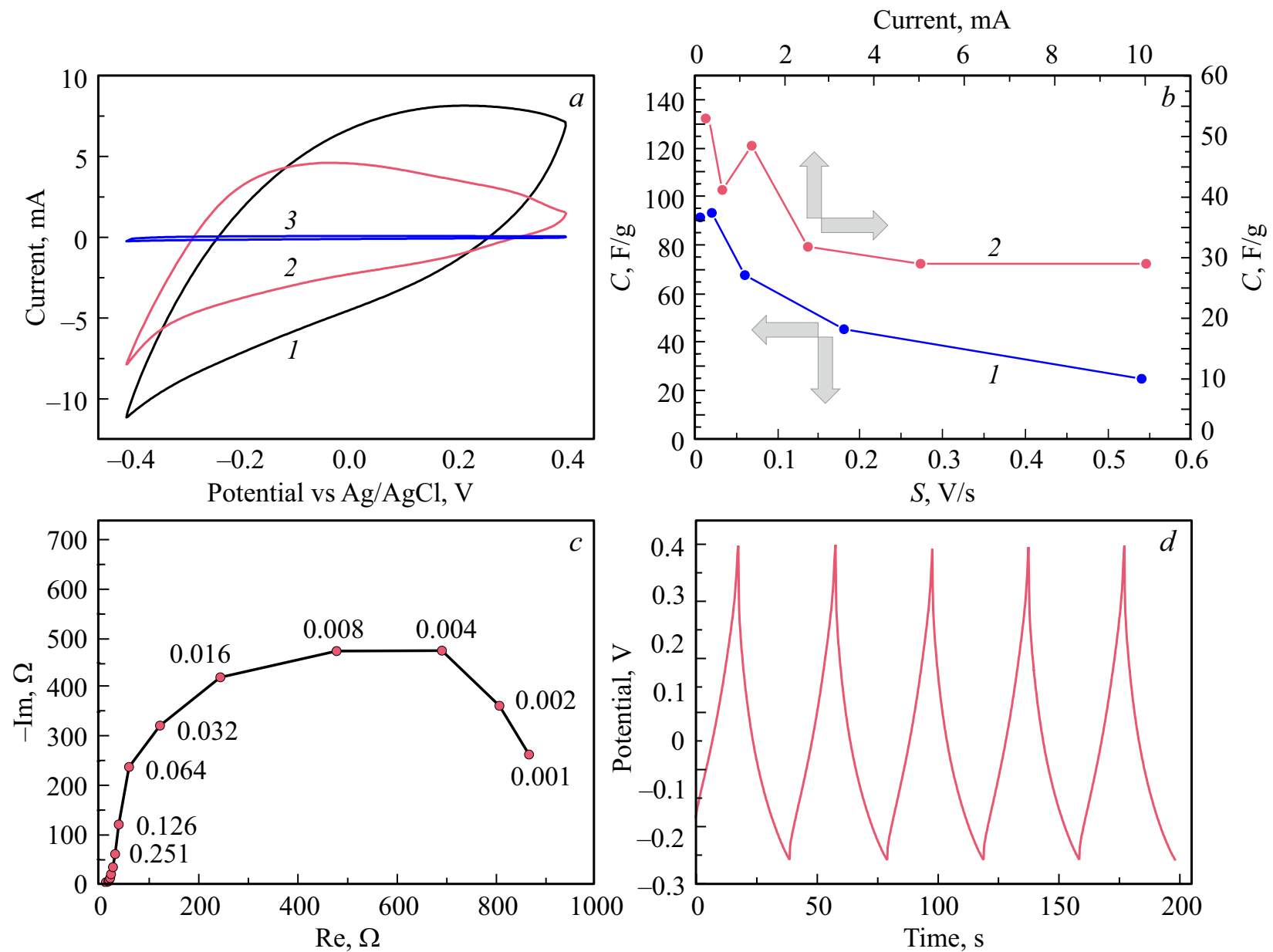

Рис. 3. Электрохимические характеристики стального электрода с впрессованным порошком вольфрама: $a-$ вольтамперограмма при скорости развертки потенциала $540 \mathrm{mV} / \mathrm{s}$ (кривая 1 ) и $180 \mathrm{mV} / \mathrm{s}$ (кривая 2), для сравнения приведены CV исходного стального электрода при скорости развертки потенциала $540 \mathrm{mV} / \mathrm{s}$ (кривая 3); $b-$ полученная из данных $\mathrm{CV}$ зависимость удельной емкости электрода от скорости развертки потенциала (кривая 1), также приведена зависимость емкости электрода от тока заряда, полученная из кривых заряда-разряда; $c$ - годограф Найквиста электрода $\mathrm{c} \mathrm{W}$, рядом с экспериментальными точками указана соответствующая частота в $\mathrm{Hz} ; d$ - кривые заряда-разряда для электрода с $\mathrm{W}$ при токе $0.6 \mathrm{~mA}$.

емкостью $0.055 \mathrm{~F}$ и сопротивлением $920 \mathrm{Ohm}$. Соответственно удельная емкость, оцененная из данных по импендансометрии, составила $92 \mathrm{~F} / \mathrm{g}$.

Проведены также гальваностатические измерения заряда-разряда при постоянной плотности тока, ток через образец варьировался в интервале от $0.3 \mathrm{~mA}$ до $10 \mathrm{~mA}$. На рис. $3, d$ показана кривая заряд-разряд для электрода с вольфрамом при токе $0.6 \mathrm{~mA}$, а на рис. 3, $b$ (кривая 2) - зависимость емкости от тока, полученная из измерений заряд-разряд. Значение емкости при низком значении тока около $53 \mathrm{~F} / \mathrm{g}$. Заметим, что определенная тремя вышеперечисленными методиками емкость электрода из нержавеющей стали с впрессованным порошком наноразмерного вольфрама имеет близкие значения.

Обращает внимание псевдоемкостной характер кривых циклической вольтамперометрии (рис. $3, a$ ). Такое поведение характерно для очень тонких, субмикронных пленок $\mathrm{WO}_{3}$ [15]. Таким образом, наблюдаемая большая емкость электродов может быть отнесена к пленке оксида вольфрама на поверхности синтезированных наночастиц вольфрама. Субмикронный тонкий слой оксида на поверхности металлического вольфрама должен эффективно участвовать в создании электрохимической емкости, поскольку пленка оксида, выросшая на поверхности наночастиц вольфрама, имеет хороший электрический контакт с объемом металлической частицы. Высокая удельная поверхность электрода обеспечивается малыми размерами наночастиц вольфрама. В свою очередь наночастицы из металлического вольфрама, в отличие от частиц оксида вольфрама с низкой электропроводностью, создают хороший электрический контакт с металлической подложкой через туннельно-тонкий слой окисла. Поэтому предложенный в настоящей работе подход к созданию конденсаторного электрода с использованием металлических наночастиц, покрытых тонким слоем оксида, может иметь преимущество перед системой из оксидных частиц. 


\section{4. Заключение}

На примере наночастиц вольфрама реализован новый подход для получения материала электродов конденсаторов с высокой емкостью, основанный на использовании наноразмерных металлических частиц, покрытых субмикронной пленкой естественного окисла. Определены режимы получения нанопорошков вольфрама с контролируемыми размерами в зависимости от технологических условий синтеза. Наночастицы вольфрама получены путем термического восстановления оксида вольфрама в водороде. Измерены электрохимические характеристики электродов, полученных с добавлением синтезированных наночастиц вольфрама. Для емкости электрода, определенной тремя электрохимическими методами $(\mathrm{CV}$, импедансной спектроскопии и характеристики заряда-разряда), получены близкие значения низкочастотной емкости в интервале $\sim 50-90$ F/g. Наблюдаемая высокая емкость электродов возникает благодаря субмикронной пленке оксида вольфрама на поверхности синтезированных наночастиц вольфрама.

\section{Список литературы}

[1] C. Dhand, N. Dwivedi, X.J. Loh, A.N.J. Ying, N.K. Varma, R.W. Beuerman, R. Lakshminarayanan, S. Ramakrishna. RSC Advances 5, 105003 (2015).

[2] V.V. Makarov, A.J. Love, O.V. Sinitsyna, S.S. Makarova, I.V. Yaminsky, M.E. Taliansky, N.O. Kalinina. Acta Nature 6, 35 (2014).

[3] Patrick T. Moseley. Meas. Sci. Technol. 28, 082001 (2017).

[4] Ю.С. Гайдук, О.Г. Реутская, А.А. Савицкий, И.А. Таратын. Приборы и методы измерений 7, 41 (2016).

[5] В.В. Зуев, Р.И. Романов, В.Ю. Фоминский, М.В. Демин, В.В. Григорьев, В.Н. Неволин. ФТП 49, 1262 (2015).

[6] B. Urasinska-Wojcik, T.A. Vincent, M.F. Chowdhury, J.W. Gardner. Sensors Actuators B 239, 1051 (2017).

[7] Minkyu Cho, Inkyu Park. J. Sensor Sci. Technol. 25, 103 (2016).

[8] Y. Alesanco, A. Vi nuales, J. Rodriguez, R. Tena-Zaera. Materials 11, 414 (2018).

[9] Alice Lee-Sie Eh, Alvin WeiMingTan, Xing Cheng, Shlomo Magdassi, Pooi See Lee. Energy Technol. 6, 33 (2018).

[10] О.Я. Березина, Д.А. Кириенко, Н.П. Маркова, Г.Б. Стефанович. Письма в ЖТФ 41, 7 (2015).

[11] В.Ю. Фоминский, С.Н. Григорьев, Р.И. Романов, М.А. Волосова, А.И. Грунин, Г.Д. Тетерина. Письма в ЖТФ 42, 1 (2016).

[12] Nan Cui, Wenpeng Li, Zengfeng Guo, Xun Xu, Hongxia Zhao. Catalysts 8, 225 (2018).

[13] P. Dong, G. Hou, X. Xi, R. Shao, F. Dong. Environ. Sci.: Nano 4, 539 (2017).

[14] C. Byrnea, G. Subramanian, S.C. Pillai. J. Environmental Chem. Eng. 3, 8 (2017).

[15] Zhenyin Hai, Mohammad Karbalaei Akbari, Zihan Wei, Chenyang Xue, Hongyan $\mathrm{Xu}$, Jie $\mathrm{Hu}$, Serge Zhuiykov. Electrochim. Acta 246, 625 (2017).

[16] Zijiong Li, Zhihua Zhou, Gaoqian Yun, Kai Shi, Xiaowei Lv, Baocheng Yang. Nanoscale Res. Lett. 8, 473 (2013).
[17] Meijia Qiu, Peng Sun, Liuxue Shen, Kun Wang, Shuqin Song, Xiang Yu, Shaozao Tan, Chuanxi Zhao, Wenjie Mai. J. Mater. Chem. A 4, 7266 (2016).

[18] O.V. Tolochko, O.G. Klimova, S.S. Ordanian, D.I. Cheong, Y.M. Kim. Rev. Adv. Mater. Sci. 21, 192 (2009).

[19] T. Acsente, R.F. Negrea, L.C. Nistor, C. Logofatu, E. Matei, R. Birjega, C. Grisolia, G. Dinescu. Eur. Phys. J. D 69, 161 (2015).

[20] P.K. Sahoo, S.S. Kalyan Kamal, M. Premkumar, T. Jagadeesh Kumar, B. Sreedhar, A.K. Singh, S.K. Srivastava, K. Chandra Sekhar. Int. J. Refractory Met. \& Hard Mater. 27, 784 (2009).

[21] A.G. Souza Filho, P.T.C. Freire, O. Pilla, A.P. Ayala, J. Mendes Filho, F.E.A. Melo, V.N. Freire, V. Lemos. Phys. Rev. B 62, 3699 (2000).

Редактор К.В. Емцев 